\title{
BMJ Open Prevalence and clinical impact of recreational drug consumption in people living with HIV on treatment: a cross-sectional study
}

\author{
Noe Garin, ${ }^{1,2}$ Beatriz Zurita, ${ }^{1}$ Cesar Velasco, ${ }^{3,4}$ Anna Feliu, ${ }^{1}$ Mar Gutierrez, ${ }^{5,6}$ \\ Montserrat Masip, ${ }^{1}$ M Antonia Mangues ${ }^{1,7}$
}

To cite: Garin N, Zurita B, Velasco C, et al. Prevalence and clinical impact of recreational drug consumption in people living with HIV on treatment: a cross-sectional study. BMJ Open 2017;7:e014105. doi:10.1136/bmjopen-2016014105

- Prepublication history for this paper is available online. To view these files please visit the journal online (http://dx.doi.org/10.1136/ bmjopen-2016-014105).

Received 31 August 2016 Revised 9 December 2016 Accepted 12 December 2016

CrossMark

For numbered affiliations see end of article.

Correspondence to Dr Noe Garin; ngarin@santpau.cat

\section{ABSTRACT}

Objectives: Drug interactions, poor adherence to medication and high-risk sexual behaviour may occur in individuals with HIV using recreational drugs. Thus, we aimed to assess the prevalence of recreational drugs use and to explore its clinical impact in HIV patients on treatment.

Methods: Observational, cross sectional, study conducted in a 700 bed university hospital, Barcelona, Spain. A total of 208 adults living with HIV on treatment were included. A questionnaire was administered by clinical pharmacists, including evaluation of sociodemographic variables, past 12-month drug consumption, adherence to antiretrovirals (Simplified Medication Adherence Questionnaire) and high-risk sexual behaviour (condomless sex/multiple partners). Additional data were obtained from clinical records. Recreational drugantiretroviral interactions were checked in reference databases. Prevalence was calculated for $5 \%$ precision and $95 \% \mathrm{Cl}$. Crude and adjusted binary logistic regressions were performed to identify associations between recreational drug use and adherence problems, and between recreational drug use and highrisk sexual behaviour.

Results: From the overall sample, 92 participants $(44.2 \%)$ consumed recreational drugs over the past 1 year. Of these, $44(48.8 \%)$ had used different types of recreational drugs in this period. We detected 11 recreational substances, including sildenafil and nitrites. The most consumed drugs were: cannabis $(68.5 \%)$, cocaine $(45.5 \%)$, nitrites $(31.5 \%)$, sildenafil (28.3) and ecstasy (19.6\%). Relevant interactions occurred in $46(50 \%)$ of the individuals consuming drugs. Recreational drug consumption was found to be related to adherence problems with antiretrovirals (OR: $2.51(95 \% \mathrm{Cl} 1.32$ to 4.77$) \mathrm{p}=0.005)$ and high-risk sexual behaviour (OR: 2.81 (95\% Cl 1.47 to 5.39 ) $\mathrm{p}=0.002$ ).

Conclusions: Recreational drugs are frequently used by HIV patients on treatment. Classical drugs and new substances consumed in sexual context are usual. Recreational drug consumption interferes with several clinical outcomes, including potentially relevant interactions between drugs and antiretrovirals,

\section{Strengths and limitations of this study}

- We studied the prevalence of recreational drug consumption in people living with HIV on treatment and its association with relevant clinical outcomes.

- The high prevalence and specific patterns of recreational drug use found in our study may vary across countries according to sociodemographic and lifestyle characteristics.

- Relevant theoretical interactions between recreational and antiretroviral drugs occurred in half of the patients using recreational drugs. To what extent these interaction may lead to clinically relevant interactions is uncertain.

- Adherence problems with the antiretroviral treatment in the individuals consuming recreational drugs may result in treatment failure depending on the recreational drug patterns of use, the degree of non-compliance and the pharmacokinetic profile of antiretrovirals.

- Owing to the cross-sectional nature of the study, causality cannot be totally inferred.

adherence problems and high-risk sexual behaviour. Thus, there is the urgent need of implementing patientcentred care involving recreational drug consumption.

\section{INTRODUCTION}

HIV continues to be a major public health challenge, with two million new infections globally in 2014. ${ }^{1}$ In Spain, about 150000 people were estimated to live with HIV in $2015 .^{2}$ The incidence rate was 9.34 cases per 100000 inhabitants in 2014, higher than the average incidence in the European Union. ${ }^{3}$ Among the new cases in Spain, 53.9\% were men who have sex with men (MSM), followed by heterosexuals $(26.0 \%)$ and injecting drug users $(3.4 \%) .{ }^{3}$ In contrast with the 
spread of HIV transmission, the effectiveness of highly active antiretroviral therapy (HAART) has translated into a decrease in mortality by $42 \%$ since 2004 globally. ${ }^{1}$ Mortality reduction in people living with HIV (PLWHIV), along with improved tolerability of newer drugs, have led to consider HIV as a chronic condition. ${ }^{4}$ Consequently, there is a need for a clinical approach in which care of PLWHIV is tailored to each individual's needs. This implies addressing conventional concerns such as linkage to care, and emerging issues such as recreational drug consumption.

It is estimated that almost a quarter of the adult population in Europe have tried illicit drugs at some point in their lives, being cannabis, cocaine, amphetamines and ecstasy the most consumed in the general population. ${ }^{5}$ Some studies have found a great proportion of recreational drug consumption in groups at risk or with great prevalence of HIV infection, especially for MSM, in countries such as the USA. ${ }^{6}{ }^{7}$ In Europe, the EMIS study reported data on recreational drug use in MSM, showing poppers, cannabis and 'sex drugs' as especially prevalent. ${ }^{8}$ As for Spain, this relevant study showed cannabis, poppers, sildenafil, cocaine and 3,4-methylenedioxymethamphetamine (ecstasy) as the most consumed substances over the past 12 months. ${ }^{9}$ However, only 23\% of the individuals in Spain reported being HIV-positive, as this was not the target group of the study. ${ }^{8}{ }^{9}$ Unlike the case of injecting drug users, with clear evidence of poor HIV-related outcomes and specific recommendations, ${ }^{10}$ interest in recreational drugs is recent in the HIV field. A previous, systematic review found 12 articles reporting prevalence data on recreational drug use in PLWHIV in Europe. ${ }^{11}$ Relevant use of recreational drugs was found in these studies. Moreover, polydrug consumption, defined as the use of various drugs over a period of time, was about $50 \%$ in some cases. However, most of the included studies collected data on a limited number of recreational drugs as they primarily focused on other topics and, therefore, methods varied greatly across them. Also, participants were included regardless of receiving HAART in most studies. According to the review results, with the exception of extensive, methodologically sound studies in countries such as the UK, ${ }^{12}$ little is known about the use of recreational drugs in many European countries, including Spain.

Consumption of recreational drugs may have relevant clinical consequences for PLWHIV who are on HAART. First, its use has been described as a factor contributing to non-adherence to HAART. ${ }^{13}$ Recreational drug use may lead to low disease awareness, temporary cognitive impairment (depending on the substance) and may interfere with daily routine, which would be related to adherence problems. ${ }^{13}$ Second, interactions between recreational drugs and HAART may appear and lead to potential toxic effects or insufficient antiretroviral plasma concentrations. ${ }^{14}$ Drug efflux transporters and cytochrome P450 (CYP) are the main factors apparently involved. ${ }^{15}$ Additionally, adherence problems are known to appear when individuals prefer not to take their antiretroviral medication in order to prevent these potential interactions. ${ }^{16}$ Third, recreational drug consumption could be associated with a high-risk sexual behaviour potentially leading to the acquisition of sexual transmitted diseases (STD) in PLWHIV using drugs. For example, recent results from the ASTRA study showed the independent relationship between increasing polydrug use and increasing prevalence of condomless sex in HIV-diagnosed MSM in London, 85\% of whom were under HAART. ${ }^{12}$ This potential association should be emphasised since the prevalence of chemsex, a term used to describe sexual relationships under the influence of certain psychoactive substances, ${ }^{17}$ has become increasingly popular in certain areas over the past few years.

Despite the potential clinical impact of recreational drug issues, guidelines on HIV antiretroviral therapy have poorly incorporated these elements. ${ }^{11}$ Guidelines tend to include general claims but usually lack specific recommendations. This could be explained as many of the efforts in this field have focused on studying the association between recreational drug use and the risk of being infected with HIV $^{11} 1819$ rather than assessing the impact of recreational drugs on people already living with HIV. Clinicians, researchers and policymakers may not be fully aware of the real magnitude of the problem since both the prevalence and the clinical impact of recreational drug use on PLWHIV is unclear, especially referring to those people on treatment. This is especially relevant for countries with very scarce data on this topic; such is the case of Spain.

Thus, the aim of the current study was to examine the prevalence of recreational drug consumption on a representative sample of adult PLWHIV on HAART, and also to explore the clinical impact of these drugs at three levels: adherence to medication, interactions between recreational drugs and HAART and high-risk sexual practices.

\section{METHODS}

\section{Study design}

This hospital-based, observational, cross-sectional study was conducted in a 700 bed University Hospital, between April 2015 and December 2015. This reference hospital services a local population of about 400000 people in Barcelona (Spain), including 1500 adult PLWHIV on HAART.

\section{Sample and procedures}

The sample included non-institutionalised adults over 18 years old living with HIV and who were on HAART at the time of the interview. Individuals with severe cognitive decline, with language barriers, needing a legal representative, starting their HAART medication since the past 30 days or already enrolled in other studies were 
considered not eligible. Participants were recruited on clinical visits to the Hospital Outpatients Pharmacy during the dispensing process (Monday-Friday; 08:0015:00) to maximise the access and quality of the pharmacist-patient interaction. All interviewers were experienced hospital pharmacists who had participated in the questionnaire design. The final response rate was 89.3\% (from a total of 233 individuals invited to participate). The final analysis consisted of 208 participants.

\section{Data collection and variable definitions}

Data were obtained from a short survey questionnaire administered to the participants by specialist clinical pharmacists. This questionnaire focused on recreational drug consumption, adherence to medication, sexual behaviour and specific sociodemographic information. Additionally, participants were informed that supplementary information would be collected from electronic clinical records. These supplementary data included variables related to the HIV condition at the time of the interview: HAART, previous viral load, previous CD4 cell count, time on treatment, time from HIV diagnosis, comorbidities and medication other than HAART. Last viral load and last CD4 cell count referred to results from blood tests conducted over the past 4 weeks from the questionnaire response; last viral load category 'undetectable' was defined as $<20$ copies $/ \mathrm{mL}$; comorbidities included all chronic conditions obtained from primary care/hospital clinical records; medication included all chronic medication other than HAART obtained from primary care/hospital clinical records. Sociodemographic variables included age, gender, educational level, marital status, country of birth, income, urbanicity (10 000+ inhabitants was considered urban), employment status, HIV transmission route, use of classical IV drugs (heroin, cocaine, morphine) and alcohol consumption. Unhealthy alcohol consumption was assessed through a single screening question 'How many times in the past year have you had X or more drinks in a day?' (where $\mathrm{X}$ was five for men and four for women, and a response of one or more was considered positive).$^{20}$

As for recreational drug consumption, we used one question assessing the use of certain substances over the past 12 months. There is evidence that the use of a single question for this purpose is valid for screening and preliminary evaluation of the use of substances of abuse compared with long questionnaires. ${ }^{20}$ The list of drugs included cannabis, cocaine, amphetamines (including crystal methamphetamine), ecstasy, $\gamma$-hydroxybutyric acid (GHB), ketamine, mephedrone, lysergic acid diethylamide (LSD), erection enhancing medication (eg,: sildenafil) and nitrites (poppers). A list of frequently-used synonyms was also used to ensure drugs could easily be identified by patients. Adherence to HAART was assessed by means of the Simplified Medication Adherence Questionnaire (SMAQ), a 6-item, validated tool. ${ }^{21}$ High-risk sexual behaviour was evaluated with two questions according to the previous literature: ${ }^{12} 2223$ a five-categories Likert question relating to the frequency of condom use in sexual intercourse, and a question on the number of sexual partners $(\geq 10)$ over the past 12 months. After information was collected, theoretical recreational drug-HAART interactions were checked with daily-practice interaction databases: 'http://www.hiv-druginteractions.org' by the University of Liverpool ${ }^{24}$ and 'Drug interaction Search' by Micromedex Solutions, 2015 Truven Health Analytics.

\section{Statistical analysis}

Sample size was calculated with the GRANMO calcula$\operatorname{tor}^{25}$ on the basis of determining the recreational drug consumption prevalence in our population group. We considered an approximate number of 1500 PLWHIV on treatment in our hospital, $15 \%$ prevalence of drug use in the Spanish general population ${ }^{26} 5 \%$ precision and 95\% CI. In order to ensure statistical robustness and facilitate additional statistical data analyses we finally considered an infinite sample for calculation purposes, which resulted in a minimum needed sample size over 200 participants.

Frequencies, proportions, range, mean, SD, CIs and cross tabulations were applied for descriptive analysis. $\chi^{2}$ Test, Fisher's exact test and t-test were used to measure differences in prevalence of sociodemographic and clinical variables across recreational drug consumption. $\chi^{2}$ Test was also used to assess differences in adherence to ART medication and measures of sexual risk behaviour across recreational drug consumption. Crude and adjusted binary logistic regressions were used to examine the relationship between recreational drug consumption and the existence of potential problems regarding adherence to HAART. Variables used for bivariate models considered those that are supposed to impact on adherence according to the literature: age, gender, education level, marital status, household income, employment, country, alcohol consumption and pill burden. The multivariate logistic regression model included those variables with an association in the bivariate analyses defined as $\mathrm{p}<0.1$ (gender, age, country of origin, education level, recreational drug consumption). Results are reported as unadjusted and adjusted ORs with 95\% CI. Analogous procedures were used to examine the association between recreational drug consumption and high-risk sexual behaviour, defined as having 10 or more sexual partners over the past 12 months and/or declaring condomless sex during this period. In this case, variables in the bivariate models included age, gender, education level, marital status, household income, employment, country, alcohol consumption and transmission route. In its corresponding multivariate analysis model, apart from the aforementioned statistical procedures (excluding marital status only), we excluded additional variables that measured the same construct as other variables of the model 
(gender, alcohol and employment were excluded). Analyses were performed with IBM SPSS statistics V.19.

\section{Ethics statement}

The study was approved by the reference Clinical Research Ethics Committee. Additionally, an independent community representative reviewed the protocol to ensure patient-oriented evaluation and suitability of the study. Written informed consent was obtained from all participants, including the acceptance of data collection from the questionnaire and the revision of clinical records. All investigators worked according to the principles expressed in the Declaration of Helsinki.

\section{RESULTS}

The study population consisted of 208 participants. Participants mean age was 46.8 years (SD: 10.4 years; range: $24-75$ years). Practically all individuals lived in urban areas, with $80 \%$ of them being men. Regarding their HIV management, $83.2 \%$ had undetectable HIV viral load and $35.6 \%$ were receiving a single-tablet treatment at the time of the interview. A summary of the full list of sociodemographic and clinical data is available at table 1 .

As for recreational drug consumption, 92 (44.2\%) participants declared having consumed drugs over the past 12 months (table 2). Of them, $44(47.8 \%)$ had taken two or more drugs during that period. As for the drugs consumed, we found 11 recreational drugs, with cannabis $(68.5 \%)$, cocaine $(45.5 \%)$, poppers $(31.5 \%)$ and erection enhancing substances $(28.3 \%)$ being the most consumed drugs.

Moderate-to-severe, potential and theoretical interactions were found in 46 participants, half of the patients consuming drugs during the past 12 months, as a result of the search in interactions databases with respect to HAART regimens and recreational drugs consumed by these individuals. HAART involved in these interactions were: ritonavir-boosted protease inhibitors, some nonnucleoside reverse transcriptase inhibitors and cobicistatboosted elvitegravir. All recreational drugs except for LSD and poppers were found to have relevant potential interactions in some individuals. Interactions distribution across recreational drugs is presented at table 3 . Problems with adherence were found in $64.1 \%$ of the individuals using recreational drugs and in $44.8 \%$ of the non-users. Condomless sex and having 10+ different sexual partners during the past year occurred in 49 $(53.3 \%)$ and $31(33.7 \%)$ individuals using drugs, respectively (table 4 ).

Table 5 shows the crude and adjusted logistic regression ORs for the association between recreational drug consumption and the existence of adherence problems with HAART. After adjusting for covariates, recreational drug consumption and educational level were revealed to be associated with adherence problems (OR: 2.51 (95\% CI 1.32 to 4.77 ) $\mathrm{p}=0.005$; OR (secondary vs primary level): 2.56 (95\% CI 1.07 to 6.14) $\mathrm{p}=0.035$, respectively). Also, recreational drug consumption, age and income was associated with sexual risk behaviour after adjusting for covariates (OR: 2.81 (95\% CI 1.47 to 5.39) $\mathrm{p}=0.002$; OR: 0.96 (95\% CI 0.93 to 0.99 ) $\mathrm{p}=0.032$; OR: 0.48 (95\% CI 0.25 to 0.91$) \mathrm{p}=0.025$, respectively). There were no missing data for recreational drug use, clinical variables and most sociodemographic variables. Information on employment status and education level was missing in $3.4 \%$ and $6.6 \%$ of the participants, respectively. We did not impute these variables as we could not guarantee whether these data were missing at random.

\section{DISCUSSION}

Our study found a relevant prevalence of recreational drug use among PLWHIV on HAART in Spain. A great proportion of the patients consuming recreational drugs had potentially severe interactions between these drugs and their HAART. Moreover, relationships between the use of drugs and other negative clinical outcomes such as problems with adherence to HAART and high-risk sexual behaviour have been detected, which are also essential for better understanding and management of drug consumption in PLWHIV.

Few studies have previously focused on recreational drug use in PLWHIV in Europe, especially in countries such as Spain. The ASTRA study included 2248 MSM living with HIV from eight outpatient clinics in the UK, with $85 \%$ on HAART. $^{12}$ In that case, they found a prevalence of recreational drug consumption in the past 3 months of about $51 \%$. Our results, although slightly lower than that in the ASTRA Study, confirm the high prevalence of recreational drug consumption in a specific area of Spain. Apart from the prevalence of use, we found certain differences compared with the ASTRA study. For example, in our study cannabis was the most frequent drug, doubling figures of nitrites, the most common drug in the ASTRA study. In fact, cannabis and cocaine, the drugs most frequently used in the general population in Spain, were found to be the most consumed in our study. ${ }^{5}$ We also found a high prevalence of sex-related drug use, including nitrites and erection enhancing medication, such as sildenafil. Previous studies in PLWHIV reported high prevalence figures on these drugs in several European countries that confirm the idiosyncrasy of drug consumption in this population. ${ }^{122728}$ Coadministration of sildenafil and nitrites is contraindicated because of their increased cardiovascular effects, ${ }^{29}$ so that interviewers provided information to individuals who reported using both substances together.

It is worth highlighting the number of different recreational drugs detected in the study, along with the prevalence of individuals who consumed several drugs over the past 12 months. We detected 11 recreational drugs, 9 of them with prevalence over $10 \%$ among the 
Table 1 Description of the sample

\begin{tabular}{|c|c|c|c|c|}
\hline & $\begin{array}{l}\text { Total sample } \\
(\mathrm{n}=208)\end{array}$ & $\begin{array}{l}\text { Non-recreational drug } \\
\text { users }(n=116)\end{array}$ & $\begin{array}{l}\text { Recreational drug } \\
\text { users }(n=92)\end{array}$ & p Value \\
\hline \multicolumn{5}{|l|}{ Sociodemographic variables } \\
\hline Age (mean, SD) (years) & $46.8(10.4)$ & $48.6(10.8)$ & $44.5(9.5)$ & 0.004 \\
\hline \multicolumn{4}{|l|}{ Gender (n, \%) } & 0.001 \\
\hline Male & $167(80.3 \%)$ & $84(72.4 \%)$ & $83(90.2 \%)$ & \\
\hline Female & $41(19.7 \%)$ & $32(27.6 \%)$ & $9(9.8 \%)$ & \\
\hline \multicolumn{4}{|l|}{ Education (n, \%) } & 0.042 \\
\hline$\leq$ Primary & $51(26.3 \%)$ & $36(33.0 \%)$ & $15(17.6 \%)$ & \\
\hline Secondary & $92(47.4 \%)$ & $49(45.0 \%)$ & $43(50.6 \%)$ & \\
\hline$\geq$ Tertiary & $51(26.3 \%)$ & $24(22.0 \%)$ & $27(31.8 \%)$ & \\
\hline \multicolumn{4}{|l|}{ Country of origin $(n, \%)$} & 0.045 \\
\hline Spain & $129(62.0 \%)$ & $79(68.1 \%)$ & $50(54.3 \%)$ & \\
\hline Other & $79(38.0 \%)$ & $37(31.9 \%)$ & $42(68.1 \%)$ & \\
\hline \multicolumn{4}{|l|}{ Location (n, \%) } & 1.000 \\
\hline Rural & $5(2.4 \%)$ & $3(2.6 \%)$ & $2(2.2 \%)$ & \\
\hline Urban & $203(97.6 \%)$ & $113(97.4 \%)$ & $90(97.8 \%)$ & \\
\hline \multicolumn{4}{|l|}{ Employment (n, \%) } & 0.758 \\
\hline Working & $140(69.7 \%)$ & $78(70.9 \%)$ & $62(68.1 \%)$ & \\
\hline Unemployed & $61(30.3 \%)$ & $32(29.1 \%)$ & $29(31.9 \%)$ & \\
\hline \multicolumn{4}{|l|}{ Marital status (n, \%) } & 0.050 \\
\hline Married/cohabiting & $96(46.2 \%)$ & $61(52.6 \%)$ & $35(38.0 \%)$ & \\
\hline Single & $112(53.8 \%)$ & $55(47.4 \%)$ & $57(62.0 \%)$ & \\
\hline \multicolumn{4}{|l|}{ Household income (n, \%) } & 0.071 \\
\hline$\leq$ Median & $105(50.5 \%)$ & $52(44.8 \%)$ & $53(57.6 \%)$ & \\
\hline$>$ Median & $103(49.5 \%)$ & $64(55.2 \%)$ & $39(42.4 \%)$ & \\
\hline \multicolumn{4}{|l|}{ Alcohol consumption ( $\mathrm{n}, \%)$} & 0.001 \\
\hline Non-consumer & $120(57.7 \%)$ & $79(68.1 \%)$ & $41(44.6 \%)$ & \\
\hline Consumer & $88(42.3 \%)$ & $37(31.9 \%)$ & $51(55.4 \%)$ & \\
\hline \multicolumn{4}{|l|}{ Classical IV drugs (n, \%) } & - \\
\hline Non-user & $206(99.0 \%)$ & $116(100 \%)$ & $90(97.8 \%)$ & \\
\hline User & $2(1.0 \%)$ & - & $2(2.2 \%)$ & \\
\hline \multicolumn{4}{|l|}{ Transmission route $(\mathrm{n}, \%)$} & 0.001 \\
\hline Heterosexual/IV drugs use/transfusion & $87(41.8 \%)$ & $61(52.6 \%)$ & $26(28.3 \%)$ & \\
\hline & $121(58.2 \%)$ & $55(47.4 \%)$ & $66(71.7 \%)$ & \\
\hline \multicolumn{5}{|l|}{ Clinical variables } \\
\hline \multicolumn{4}{|l|}{ ART pill burden (n, \%) } & 0.383 \\
\hline 1 pills/day & $74(35.6 \%)$ & $39(33.6 \%)$ & $35(38.0 \%)$ & \\
\hline 2 pills/day & $67(32.2 \%)$ & $42(36.2 \%)$ & $25(27.2 \%)$ & \\
\hline$\geq 3$ pills/day & $67(32.2 \%)$ & $35(30.2 \%)$ & $32(34.8 \%)$ & \\
\hline \multicolumn{4}{|l|}{ Viral load $(n, \%)$} & 0.358 \\
\hline Undetectable & $173(83.2 \%)$ & $99(85.3 \%)$ & $74(80.4 \%)$ & \\
\hline Detectable & $35(16.8 \%)$ & $17(14.7 \%)$ & $18(19.6 \%)$ & \\
\hline \multicolumn{4}{|l|}{ CD4 cell count ( $\mathrm{n}, \%)$} & 0.054 \\
\hline$<500$ cells $/ \mu \mathrm{L}$ & $53(25.5 \%)$ & $36(31.0 \%)$ & $17(18.5 \%)$ & \\
\hline$\geq 500$ cells $/ \mu \mathrm{L}$ & $155(74.5 \%)$ & $80(69.0 \%)$ & $75(81.5 \%)$ & \\
\hline Time on treatment (mean, SD) & $10.4(7.1)$ & $12.0(7.2)$ & $8.3(6.4)$ & 0.001 \\
\hline Time diagnosed (mean, SD) & $12.8(8.2)$ & $14.5(8.1)$ & $10.7(7.8)$ & 0.001 \\
\hline \multicolumn{4}{|l|}{ Other comorbidity (n, \%) } & 0.854 \\
\hline No & $36(17.3 \%)$ & $21(18.1 \%)$ & $15(16.3 \%)$ & \\
\hline Yes & $172(82.7 \%)$ & $95(81.9 \%)$ & $77(83.7 \%)$ & \\
\hline \multicolumn{4}{|l|}{ Other medication (n, \%) } & 0.381 \\
\hline No & $72(34.6 \%)$ & $37(31.9 \%)$ & $35(38.0 \%)$ & \\
\hline Yes & $136(65.4 \%)$ & $79(68.1 \%)$ & $57(62.0 \%)$ & \\
\hline \multicolumn{5}{|c|}{$\begin{array}{l}\text { Frequencies, proportions, means and SDs are displayed. } \chi^{2} \text { Test (for } 2 \times \mathrm{N} \text { tables) and t-test (for continuous variables) were performed to } \\
\text { compare across recreational drug consumption (also, Fisher's exact test was used for variables 'location' and 'classical IV drugs'). Variables: } \\
\text { age, time on treatment and time diagnosed are expressed in years. Employment category 'unemployed' included unemployed and inactive } \\
\text { population such as homemakers and retired; Marital status category 'single' included: single, separated, divorced and widowed; Household } \\
\text { income 'median' was } € 16000 / \text { year; Classical IV drugs included heroin, cocaine, morphine; Viral load category 'undetectable' was defined as } \\
<20 \text { copies/mL. } \\
\text { ART, antiretroviral therapy. }\end{array}$} \\
\hline
\end{tabular}


individuals taking drugs. Some of these drugs can be considered club drugs, such as ecstasy, GHB, amphetamines, speed and ketamine. Moreover, we found a relevant proportion of participants reporting drugs included in the definition of 'chemsex': GHB, metamphetamines

Table 2 Prevalence of past 12-month recreational drug consumption among individuals consuming recreational drugs $(n=92)$

\begin{tabular}{|c|c|c|}
\hline & $\begin{array}{l}\text { Number of } \\
\text { individuals (\%) }\end{array}$ & $\begin{array}{l}\text { Mean (min-max; } \\
\text { days) }\end{array}$ \\
\hline \multicolumn{3}{|l|}{ Type of drug } \\
\hline Cannabis & $63(68.5)$ & $164.5(1-365)$ \\
\hline Cocaine & $40(45.5)$ & $14.9(1-156)$ \\
\hline Poppers & $29(31.5)$ & $14.7(1-52)$ \\
\hline Sildenafil & 26 (28.3) & $12.6(1-104)$ \\
\hline Ecstasy & 18 (19.6) & $5.9(1-24)$ \\
\hline $\mathrm{GHB}$ & 14 (15.2) & $12.7(1-100)$ \\
\hline Amphetamines & $11(12.0)$ & $5.6(1-20)$ \\
\hline Speed & $11(12.0)$ & $13.45(2-52)$ \\
\hline Ketamine & $9(9.8)$ & $6.1(1-24)$ \\
\hline Mephedrone & $4(4.3)$ & $16.3(1-50)$ \\
\hline LSD & $1(1.1)$ & $1(1-1)$ \\
\hline \multicolumn{3}{|l|}{ Number of drugs } \\
\hline 1 & $48(52.2)$ & - \\
\hline 2 & $14(15.2)$ & - \\
\hline 3 & 10 (10.9) & - \\
\hline 4 & $6(6.5)$ & - \\
\hline 5 & $5(5.4)$ & - \\
\hline $6+$ & $9(9.8)$ & - \\
\hline \multicolumn{3}{|c|}{$\begin{array}{l}\text { Values calculated for the group of individuals taking recreational } \\
\text { drugs. Frequencies, proportions, means and ranges are displayed. } \\
\text { 'Mean' refers to the average consumption of each drug over the } \\
\text { past } 12 \text { months. } \\
\text { Amphetamines, include crystal meth; GHB, } \gamma \text {-hydroxybutyric acid; } \\
\text { LSD, lysergic acid diethylamide; MDMA, } \\
\text { 3,4-methylenedioxymethamphetamine (commonly known as } \\
\text { ecstasy). }\end{array}$} \\
\hline
\end{tabular}

or mephedrone. ${ }^{17}$ Apart from interactions, chemsex has been associated with high-risk sexual practices, including condomless sex or slamming, which involves injecting drugs such mephedrone or GHB. ${ }^{11} 1417$ To what extent these drugs can lead to addiction and abuse needs further study, which should take into account some related sociocultural issues such as the widespread use of geo-sexual networking apps.

The prevalence of relevant potential interactions between recreational drugs and HAART in Spain is unclear to date. The results of our study revealed a great proportion of relevant potential interactions in PLWHIV on treatment. These interactions involved 10 different recreational drugs and 3 antiretroviral groups (ritonavirboosted PIs, non-nucleoside reverse transcriptase inhibitors and cobicistat-boosted integrase inhibitors). Although several mechanisms have been described in the literature, most of the relevant interactions between recreational drugs and HAART are known to occur through the CYP metabolic pathway. ${ }^{14}{ }^{30}$ Moreover, most interactions described in the literature result in accumulation of recreational drugs or their toxic metabolites, leading to potential risk of adverse effects by these substances. As expected, that was the case in our study. However, we also found six individuals with an interaction between cannabis and atazanavir, which is known to decrease blood levels of atazanavir below its therapeutic range in $50 \%$ of the individuals on treatment with atazanavir using cannabis. ${ }^{24}$

In contrast with issues such as poor tolerability or poor adherence to medication, it may seem that potential severe interactions between recreational drugs and HAART need to be reconsidered in future clinical approaches. We hypothesise two main reasons leading to this situation: unawareness of the relevance of these interactions by clinicians and, especially, the fact that drug use can be an undisclosed issue by patients. In fact,

Table 3 Past 12-month, potential, relevant interactions between recreational drugs and antiretrovirals $(n=46)$

\begin{tabular}{|c|c|c|c|c|c|c|c|c|}
\hline & \multicolumn{3}{|c|}{ Ritonavir boosted PI } & \multicolumn{4}{|l|}{ NNRTI } & \multirow{2}{*}{$\begin{array}{l}\text { Cobicistat } \\
\text { boosted } \\
\text { INSTIs } \\
\text { Elvitegravir/c }\end{array}$} \\
\hline & Atazanavir/r & Darunavir/r & Lopinavir/r & Efavirenz & Etravirine & Nevirapine & Rilpivirine & \\
\hline Amphetamines & - & - & - & - & - & - & - & 3 \\
\hline Cannabis & 6 & - & - & - & - & - & - & - \\
\hline Cocaine & 4 & 8 & 2 & 2 & 3 & 1 & 12 & 7 \\
\hline Ecstasy & - & 4 & - & - & - & - & - & - \\
\hline $\mathrm{GHB}$ & 1 & 2 & - & - & - & - & - & - \\
\hline Ketamine & - & 2 & 1 & 1 & 1 & - & - & 1 \\
\hline Mephedrone & - & 1 & - & - & - & - & - & - \\
\hline Speed & 1 & 1 & - & 2 & - & - & - & 3 \\
\hline Sildenafil & 1 & 4 & - & 2 & 5 & 1 & - & 2 \\
\hline
\end{tabular}


Table 4 Outcomes on adherence to ART medication and measures of sexual risk behaviour over the past 12 months

\begin{tabular}{|c|c|c|c|c|}
\hline & Total sample $(n=208)$ & $\begin{array}{l}\text { Non-recreational drug } \\
\text { users }(n=116)\end{array}$ & $\begin{array}{l}\text { Recreational drug } \\
\text { users }(n=92)\end{array}$ & p Value \\
\hline Adherence to ART & & & & 0.004 \\
\hline Good adherence & $97(46.6 \%)$ & $64(55.2 \%)$ & $33(35.9 \%)$ & \\
\hline Poor adherence & $111(53.4 \%)$ & $52(44.8 \%)$ & $59(64.1 \%)$ & \\
\hline Sexual intercourse & & & & 0.001 \\
\hline Condom-protected sex & $129(62.0 \%)$ & $86(74.1 \%)$ & $43(46.7 \%)$ & \\
\hline Condomless sex & 79 (38.0\%) & $30(25.9 \%)$ & 49 (53.3.0\%) & \\
\hline Sexual partners & & & & 0.001 \\
\hline$<10$ & $164(78.8 \%)$ & $103(88.8 \%)$ & $61(66.3 \%)$ & \\
\hline$\geq 10$ & $44(21.2 \%)$ & $13(11.2 \%)$ & $31(33.7 \%)$ & \\
\hline
\end{tabular}

a recent analysis by Daskalopoulou $e t a l^{31}$ of participants on HAART from the ASTRA study found very similar prevalence of recreational drug consumption across different HAART regimens, suggesting that clinicians do not consider drug use as a relevant issue in HAART selection. The authors also claim for the need of nonjudgmental attitudes by healthcare providers when discussing drug use along with the benefits of community peer-led initiatives. $^{31}$

Adherence to HAART is essential for controlling HIV infection. The prevalence of individuals with adherence problems in our study was $64.1 \%$ in those people using recreational drugs and $44.8 \%$ in non-users. The results of the multivariate logistic regression showed a statistically significant relationship between recreational drug use and lower adherence rates. Our results agree with the ones of the ASTRA study, in which recreational drug use was associated with lower adherence rates. ${ }^{12}$ Also, as in the ASTRA study, prevalence of undetectable viral load in the group consuming recreational drugs on HAART was above $80 \%$, which highlights that consuming recreational drugs is not necessarily related to adherence problems leading to clinical complications. ${ }^{12}$ It is estimated that a minimum adherence rate of about $85 \%$ is needed to suppress RNA in about $80 \%$ of patients on HAART treatment. ${ }^{32}$ As a consequence, the number of missed doses along with the pharmacokinetic profile of antiretrovirals may modulate the final impact of treatment efficacy.

From a behavioural perspective, several aspects should be considered when interpreting the association between recreational drug consumption and adherence problems. Individuals consuming recreational drugs may be concerned by severe potential intoxications or adverse effects due to interactions between recreational drugs and medicines. This concept is known as interactive toxicity belief' ${ }^{16}$ Thus, some people may anticipate, delay or miss their HAART medication, which may partly explain the results found in our study. For example, Kalichman et $a l^{16}$ found that $35 \%$ of PLWHIV on treatment intentionally miss doses when they are using drugs, being those individuals with interactive toxicity belief at greater risk. Apart from intentional nonadherence, temporary cognitive impairment due to the use of recreational drugs may interfere with memory or routine activities and eventually impact negatively on adherence to HAART. ${ }^{13}$ To what extent each component, intentional versus non-intentional non-adherence, affects our results is unknown and should be subject of further investigations.

Finally, our results showed a clear association between the past 12-month recreational drug consumption and high-risk sexual behaviour, including condomless-sex and multiple sexual partners. Caution should be exercised in the interpretation of this result. High-risk sexual behaviour may lead to a greater risk of acquiring sexually transmitted infections by individuals consuming recreational drugs. Our results expand and complement the evidence found in previous studies which found a clear association between the use of recreational drugs and several measures of high-risk sexual practices, such as unprotected anal intercourse, group sex or multiple sexual partners. ${ }^{12} 33$ Moreover, risk of HIV transmission to other sexual partners would be low as most individuals in the study had suppressed HIV viral load, which relates to a minimal transmission risk according to the results found in the PARTNER study. ${ }^{34}$ There is however, the risk of HIV transmission in the case of individuals with detectable HIV viral load. Since alcohol and drug use can be relatively common during unprotected sexual relationships in specific population groups, interventions would also be justified to prevent HIV transmission. ${ }^{27}$ Thus, our results underline the need of comprehensive interventions aiming to prevent new HIV transmissions in specific population groups and also to reduce sexually transmitted infections in PLWHIV using recreational drugs. As aforementioned, further studies should continue exploring the risks of chemsex, as this may involve polydrug use and particularly high-risk sexual behaviour along with possible addictive-related concerns. ${ }^{12} 1417$ 


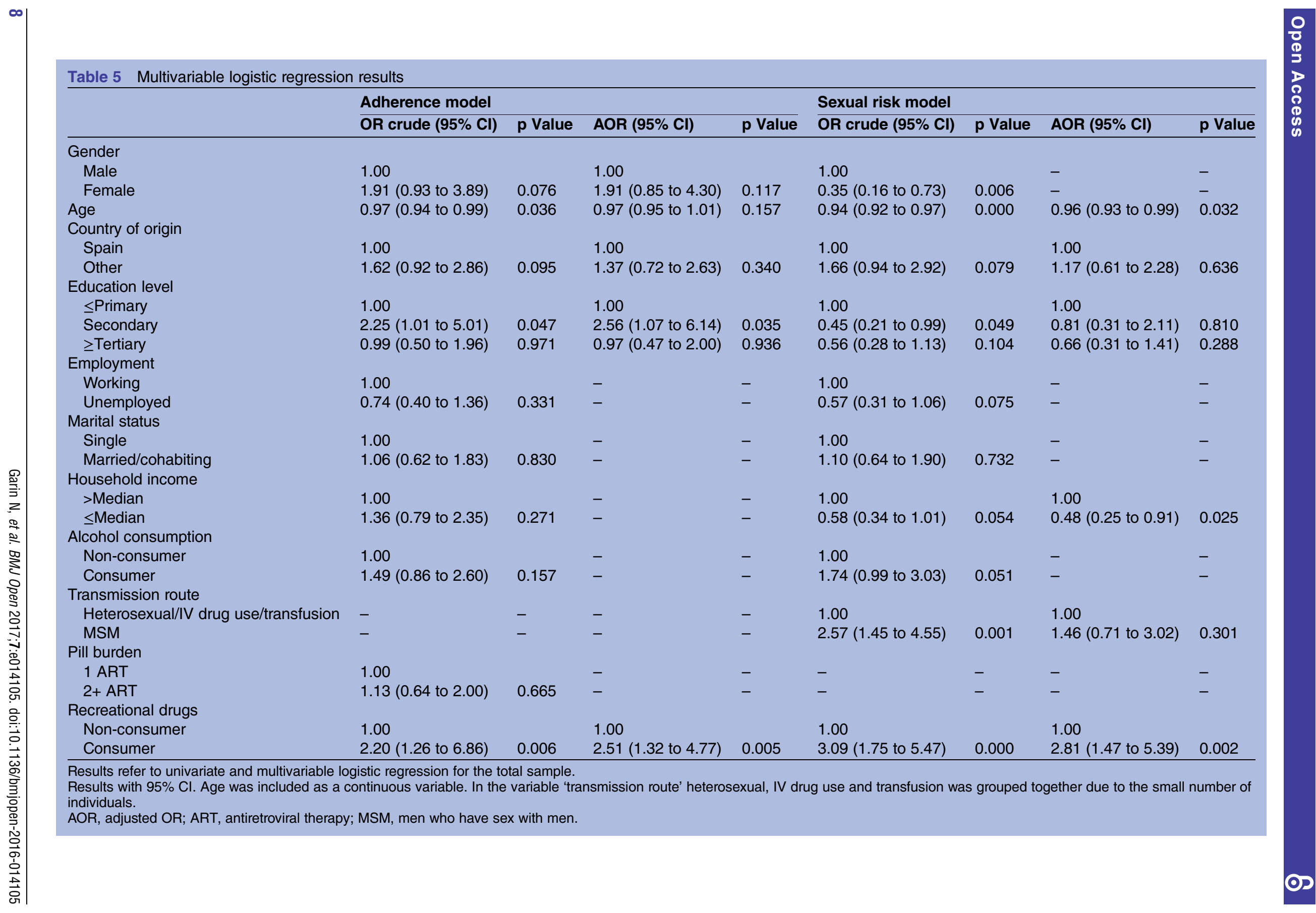

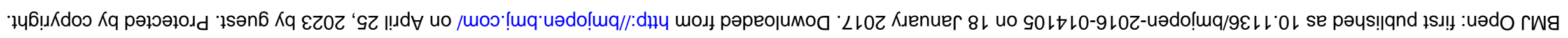


Our study has certain limitations. First, its crosssectional nature identifies associations but does not allow causal relationships to be determined. Second, we used a self-reported, interviewer-administered, data collection method that could bias the results. Some individuals may be reluctant to report drug use as it is not socially accepted and they may fear being judged by health professionals. Thus, there is the possibility that the prevalence/frequency of recreational drug use is underestimated. For the same reason, it could be the case that some of the PLWHIVs not accepting to participate in the study had some issues with accepting recreational drug use publicly. Third, our results may only apply to our geographical area or to very similar ones (urban areas with same socioeconomic level) in Spain. Extrapolation of the results to other contexts is not straightforward as recreational drug patterns are heterogeneous across countries in Europe, while differing recall periods may also make difficult comparisons of prevalence estimates with other studies. Also, since consumption patterns change with time, results on prevalence of use and their impact could differ with ours in the long term. Another limitation may be the choice of 10 different sexual partners in the past year, which could lead to potential overestimation of sexual risk behaviour, especially for MSMs who may have high partner turnover. Finally, most drug-recreational drug interaction databases base their information on theoretically expected interactions according to metabolic pathways. Lack of clinical studies on real-life interactions leads to a useful but imprecise picture on this outcome, potentially omitting certain interactions not yet described.

In conclusion, prevalence of recreational drug consumption is particularly high in PLWHIV on treatment, the use of different drugs being relatively frequent. Furthermore, the results of our study contribute to a deeper understanding of the impact of recreational drugs at various levels. First, theoretically relevant interactions occurred in half of the individuals using drugs. Clinicians should be aware of the most relevant interactions and may adapt antiretroviral therapy in certain cases according to the pharmacokinetics of the antiretrovirals and recreational drug patterns of use. Second, recreational drug use was associated with lower adherence to antiretrovirals and high-risk sexual behaviour, which may lead to a higher risk of therapy failure and STD acquisition, respectively. Recreational drug consumption should be discussed openly between health professionals and PLWHIV on treatment seeking to clarify both general and individual recreational drug-related concerns. Further exploration on possible interventions aiming to decrease negative clinical outcomes related to recreational drugs are needed to minimise their risks in PLWHIV on treatment.

\section{Author affiliations}

${ }^{1}$ Pharmacy Department, Hospital de la Santa Creu i Sant Pau, Universitat Autònoma de Barcelona, Barcelona, Spain
${ }^{2}$ Instituto de Salud Carlos III, Centro de Investigación Biomédica en Red de Salud Mental (CIBERSAM), Madrid, Spain

${ }^{3}$ Department of Preventive Medicine and Epidemiology, Hospital ClinicIDIBAPS, University of Barcelona, Barcelona, Spain

${ }^{4}$ ISGlobal, Barcelona Ctr. Int. Health Res. (CRESIB), Hospital Clínic, University of Barcelona, Barcelona, Spain

${ }^{5}$ Infectious Diseases Unit, Hospital de la Santa Creu i Sant Pau, Universitat Autònoma de Barcelona, Barcelona, Spain

${ }^{6}$ Biomedical Research Institute Sant Pau (IIB Sant Pau), Barcelona, Spain

${ }^{7}$ Instituto de Salud Carlos III, Centro de Investigación Biomédica en Red de Bioingeniería, Biomateriales y Nanomedicina (CIBER-BBN), Barcelona, Spain

Contributors NG conceived the study idea/study protocol, collected, analysed and interpreted the data and wrote the main body of the text. BZ, MM, AF participated in the protocol design, data collection and commented for intellectual content. CV, MG, MAM participated in the protocol design and commented for intellectual content. All authors were involved in writing the paper and had final approval of the manuscript. Authors agreed to be accountable for all aspects of the work in ensuring that questions related to the accuracy or integrity of any part of the work are appropriately investigated and resolved.

Funding This research received no specific grant from any funding agency in the public, commercial or not-for-profit sectors.

Competing interests None declared.

Patient consent Obtained.

Ethics approval Reference Clinical Research Ethics Committee (Hospital de la Santa Creu i Sant Pau, Barcelona, Spain).

Provenance and peer review Not commissioned; externally peer reviewed.

Data sharing statement Specific data of the study questionnaire and study results are available under request.

Open Access This is an Open Access article distributed in accordance with the Creative Commons Attribution Non Commercial (CC BY-NC 4.0) license, which permits others to distribute, remix, adapt, build upon this work noncommercially, and license their derivative works on different terms, provided the original work is properly cited and the use is non-commercial. See: http:// creativecommons.org/licenses/by-nc/4.0/

\section{REFERENCES}

1. Joint United Nations Programme on HIV/AIDS (UNAIDS). Fact sheet 2015. Global statistics, 2015. http://www.unaids.org/sites/default/files/ media asset/20150901_FactSheet_2015 en.pdf

2. Secretaría General de Sanidad, Dirección General de Salud Pública, Calidad e Innovación. Informe nacional sobre los progresos realizados en la aplicación del GARPR, España. Enero 2015diciembre 2015. Ministerio de Sanidad, Servicio Sociales e Igualdad España. 2016. http://www.unaids.org/sites/default/files/country/ documents/ESP_narrative_report_2016.pdf

3. Dirección General de Salud Pública, Calidad e Innovación. Vigilancia Epidemológica del VIH y SIDA en España, actualización 30 de junio de 2015. Ministerio de Sanidad, Servicios Sociales e Igualdad, España. 2015. http://www.msssi.gob.es/ciudadanos/enfLesiones/ enfTransmisibles/sida/vigilancia/InformeVIH_SIDA_2015.pdf

4. Deeks SG, Lewin SR, Havlir DV. The end of AIDS: HIV infection as a chronic disease. Lancet 2013;382:1525-33.

5. European Monitoring Centre for Drugs and Drug Addiction. European Drug Report. Trends and Developments. 2015. http://www. emcdda.europa.eu/system/files/publications/974/TDAT15001ENN. pdf

6. Newcomb ME, Ryan DT, Greene GJ, et al. Prevalence and patterns of smoking, alcohol use, and illicit drug use in young men who have sex with men. Drug Alcohol Depend 2014;141:65-71.

7. Hatfield LA, Horvath KJ, Jacoby SM, et al. Comparison of substance use and risky sexual behavior among a diverse sample of urban, HIV-positive men who have sex with men. J Addict Dis 2009;28:208-18.

8. The EMIS Network. EMIS 2010: the European men-who-have-sexwith-men internet survey. Findings from 38 countries. Stockholm: European Centre for Disease Prevention and Control, 2013. 
9. Folch C, Fernández-Dávila $\mathrm{P}$, Ferrer L, et al. [High prevalence of drug consumption and sexual risk behaviors in men who have sex with men]. Med Clin (Barc) 2015;145:102-7.

10. World Health Organization. WHOIConsolidated guidelines on HIV prevention, diagnosis, treatment and care for key populations. WHO Press World Heal Organ Geneva, Switzerland. World Health Organization, 2014. http://www.who.int/hiv/pub/guidelines/ keypopulations/en/

11. Garin N, Velasco C, De Pourcq JT, et al. Recreational drug use among individuals living with HIV in Europe: review of the prevalence, comparison with the general population and HIV guidelines recommendations. Front Microbiol 2015;6:690.

12. Daskalopoulou M, Rodger A, Phillips AN, et al. Recreational drug use, polydrug use, and sexual behaviour in HIV-diagnosed men who have sex with men in the UK: results from the cross-sectional ASTRA study. Lancet HIV 2014;1:e22-31.

13. Halkitis P, Palamar J, Mukherjee P. Analysis of HIV medication adherence in relation to person and treatment characteristics using hierarchical linear modeling. AIDS Patient Care STDS 2008;22:323-35.

14. Bracchi M, Stuart D, Castles R, et al. Increasing use of 'party drugs' in people living with HIV on antiretrovirals: a concern for patient safety. AIDS 2015;29:1585-92.

15. Pal D, Kwatra D, Minocha M, et al. Efflux transporters- and cytochrome P-450-mediated interactions between drugs of abuse and antiretrovirals. Life Sci 2011;88:959-71.

16. Kalichman SC, Kalichman MO, Cherry C, et al. Intentional medication nonadherence because of interactive toxicity beliefs among HIV-positive active drug users. J Acquir Immune Defic Synd 2015;70:503-9.

17. Bourne A, Reid D, Hickson F, et al. Illicit drug use in sexual settings ('chemsex') and HIV/STI transmission risk behaviour among gay men in South London: findings from a qualitative study. Sex Transm Infect 2015;91:564-8.

18. Mustanski BS, Newcomb ME, Du Bois SN, et al. HIV in young men who have sex with men: a review of epidemiology, risk and protective factors, and interventions. J Sex Res 2011;48: $218-53$.

19. Chen X, Li X, Zheng J, et al. Club drugs and HIV/STD infection: an exploratory analysis among men who have sex with men in Changsha, China. PLoS ONE 2015;10:e0126320.

20. Saitz R, Cheng DM, Allensworth-Davies D, et al. The ability of single screening questions for unhealthy alcohol and other drug use to identify substance dependence in primary care. J Stud Alcohol Drugs 2014;75:153-7.

21. Knobel H, Alonso J, Casado JL, et al. Validation of a simplified medication adherence questionnaire in a large cohort of HIV-infected patients: the GEEMA Study. AIDS 2002;16:605-13.

22. Weir SS, Roddy RE, Zekeng L, et al. Measuring condom use: asking "do you or don't you" isn't enough. AIDS Educ Prev 1998;10:293-302.

23. Weir SS, Roddy RE, Zekeng L, et al. Association between condom use and HIV infection: a randomised study of self-reported condom use measures. J Epidemiol Community Health 1999;53:417-22.

24. Liverpool HIV Pharmacology Group (LHPG). HIV drug interactions webpage. http://www.hiv-druginteractions.org/

25. Marrugat J, Vila J, Pavesi M, et al. [Estimation of the sample size in clinical and epidemiological investigations]. Med Clin (Barc) 1998;111:267-76.

26. European Monitoring Center for Drugs and Drug Addiction. 2015. http://www.emcdda.europa.eu/

27. Li J, McDaid LM. Alcohol and drug use during unprotected ana intercourse among gay and bisexual men in Scotland: what are the implications for HIV prevention? Sex Transm Infect 2014;90:125-32.

28. Schmidt AJ, Rockstroh JK, Vogel M, et al. Trouble with bleeding: risk factors for acute hepatitis $\mathrm{C}$ among HIV-positive gay men from Germany-a case-control study. PLOS ONE 2011;6:e17781.

29. Jackson G, Montorsi P, Cheitlin MD. Cardiovascular safety of sildenafil citrate (Viagra): an updated perspective. Urology 2006;68(3 Suppl):47-60.

30. Bruce RD, Altice FL, Friedland GH. Pharmacokinetic drug interactions between drugs of abuse and antiretroviral medications: implications and management for clinical practice. Expert Rev Clin Pharmacol 2008;1:115-27.

31. Daskalopoulou M, Rodger AJ, Phillips AN, et al. Prevalence of recreational drug use is indiscriminate across antiretroviral regimens of differing drug-drug interactions among MSM. AIDS 2016;30:810-12.

32. Viswanathan S, Detels R, Mehta SH, et al. Level of adherence and HIV RNA suppression in the current era of Highly Active Antiretroviral Therapy (HAART). AIDS Behav 2014;19:601-11.

33. Dirks H, Esser S, Borgmann R, et al. Substance use and sexual risk behaviour among HIV-positive men who have sex with men in specialized out-patient clinics. HIV Med 2012;13:533-40.

34. Rodger AJ, Cambiano V, Bruun T, et al. Sexual activity without condoms and risk of HIV transmission in serodifferent couples when the HIV-positive partner is using suppressive antiretroviral therapy. JAMA 2016;316:171-81. 